\title{
LONG-TERM GROWTH OF DIPLOID HUMAN FIBROBLASTS IN LOW SERUM MEDIA
}

\author{
Cheryl. Wistrom and Bryant Villeponteau \\ Department of Biological Chemistry and The Institute of Gerontology, University of Michigan, Ann Arbor, MI
}

\begin{abstract}
Hayflick and Moorhead demonstrated that diploid human fibroblasts have a limited life span when grown in media containing $10 \%$ bovine calf sera. Recent experiments have suggested that antigrowth factors in serum may be a potential contributor to the limited proliferative capacity of normal diploid cells. To reduce the concentration of inhibitory serum factors 10-fold, MRC-5 diploid fibroblasts were cultured in media with only $1 \%$ serum. Long-term culture in $1 \%$ serum requires the addition of purified growth factors to sustain proliferation. Although there are dramatic changes in cell morphology, we find that the long-term division potential of MRC-5 cells cultured in media containing $1 \%$ serum and growth factors differs little from that found with cells cultured in $10 \%$ serum. In contrast, MRC-5 cells cultured in 10\% serum and added growth factors have a somewhat extended life span. These results suggest that negative growth factors are not responsible for the limited proliferative capacity of in vitro cultured human fibroblasts. Moreover, the evidence that human fibroblasts can undergo major changes in cell morphology and still retain a normal life span raises questions about the validity of using morphological changes as indicators of cellular senescence.
\end{abstract}

Key Words: cell senescence, serum-free media, growth factors, growth inhibitors

\section{INTRODUCTION}

IN EARLY tissue culture studies (Ebeling, 1913; Carrel and Ebeling, 1921), it was reported that chicken fibroblasts had an indefinite life span. Based on this work, many of the early investigators believed that normal cells are immortal if cultured in vitro and that inhibitory factors in serum are a possible cause of aging in vivo (Ebeling, 1913; Carrel and Ebeling, 1921; Parker, 1931). In later studies it was demonstrated that normal human and chicken fibroblasts have a limited proliferative capacity in vitro (Hayflick and Moorhead, 1961; Hayflick, 1965; Hay and Strehler, 1967; Hayflick, 1977). It is now widely if not universally accepted that normal eukaryotic cells have a limited proliferative capacity in vitro which is not dependent on culture media. Based on these later experiments, the original data gathered by Carrel and

Correspondence to: B. Villeponteau, Institute of Gerontology, 300 North Ingalls, Ann Arbor, MI 48109-2007. (Received 6 June 1989; Accepted 2 October 1989) 
Ebeling have been dismissed as artifactual owing to the inadvertent addition of vigorously growing young cells during the process of cell feeding (Hayflick, 1977).

More recent studies have raised new questions about the role of serum in determining the life span of cultured cells. First, the in vitro life span of cultured human fibroblasts has been found to vary significantly with differing lots of serum (Schneider et al., 1978). Second, putative normal rat thyroid epithelial cells (Ambesi-Impiombato et al., 1980) and mouse embryonic cells (Loo et al., 1987) have been cultured indefinitely in media with little or no serum. These results have served to revive the hypothesis that the life span of cultured cells is potentially unlimited and that senescence is induced.by inhibitory serum factors.

The demonstration that some diploid rat and mouse cells have an unlimited life span in low serum (Ambesi-Impiombato et al., 1980; Loo et al., 1987) is in direct contradiction to the hypothesis that normal cells have an inherent limit to proliferation which is not determined by external serum factors. However, the interpretation of these experiments is clouded by the frequency with which rodent cells become spontaneously immortalized. The finding that a rodent cell line remains diploid does not preclude the occurrence of a transforming genetic change and some karyological abnormalities do appear in mouse cells grown in serum-free media (see Fig. 2 of Loo et al., 1987). To avoid these problems we have carried out low serum experiments using the well-defined human MRC-5 fibroblast line. We find that the culture of human MRC-5 cells in low serum does not lead to a lengthening of life span as is sometimes the case with rodent cells.

\section{MATERIALS AND METHODS}

\section{Tissue culture cells}

Human MRC-5 cells were chosen as indicator cells for these experiments since this diploid cell line has been previously used in aging experiments (Jacobs et al., 1970) and proliferates faster than WI-38 cells (Wistrom, unpublished data). The MRC-5 cell line was originally derived from normal lung tissue of a 14-week-old male fetus. We acquired the cells from the NIH Aging Cell Repository at a population doubling level (PDL) of 15. The cells were cultured in a 1:1 mixture of Dulbecco's Modified Eagle's Medium (DME) and Ham's Nutrient mixture F-12 (product \#8900, Sigma Chemical Company) containing $10 \%$ bovine fetal calf serum and 100 units $/ \mathrm{ml}$ penicillin, $50 \mu \mathrm{g} / \mathrm{ml}$ streptomycin, and $50 \mu \mathrm{g} / \mathrm{ml}$ neomycin. At a PDL of 19 , the cells were frozen in the above medium containing $10 \%$ glycerol and stored in vials submersed in liquid nitrogen. These vials of MRC-5 cells were used for all of our serum experiments.

\section{Cell passage and counting}

Confluent MRC-5 cells were washed in Balanced Salt Buffer $(15 \mathrm{mM}$ Hepes, $130 \mathrm{mM} \mathrm{NaCl}$, $5 \mathrm{mM} \mathrm{KCl}, 1 \mathrm{mM}$ sodium phosphate, and $0.3 \%$ glucose) and treated with Balanced Salt Buffer containing $0.25 \%$ trypsin (Sigma Chemical Co.). The trypsin was pipetted off after 1 $\mathrm{min}$ and the cells incubated at room temperature for 2 to $4 \mathrm{~min}$. Trypsinization was stopped by resuspending the cells in $4 \mathrm{ml}$ of DME/F12 medium containing $1 \%$ or $10 \%$ serum \pm growth factors (see below). Two aliquots of the cells from each replicate plate were counted in a Neubauer hemocytometer and the mean used to calculate the population doubling level. One quarter of the cells from each flask was then introduced into new $25 \mathrm{~cm}^{2} \mathrm{~T}$ flasks. The $\mathrm{T}$ flasks 
with loosened caps were incubated in a humidified incubator in the presence of $3.5 \% \mathrm{CO}_{2}$. In our standard protocol each PDL determination represents the mean from two replicate cultures. Cell counts on replicate plates normally differ by less than $15 \%$.

\section{Growth in low serum media}

Lots of bovine fetal calf serum (Hazelton Laboratories) were tested for serum quality by assaying for the long-term growth of MRC-5 cells. Only serum lots which could support MRC-5 growth to a population doubling level (PDL) of at least 66 were utilized in the low serum experiments. To assure serum uniformity, only one lot of fetal calf serum was used throughout an individual experiment.

In all $1 \%$ serum experiments, the normal DME/F12 media plus $1 \%$ serum was supplemented with a mix of growth factors $(10 \mathrm{ng} / \mathrm{ml}$ epidermal growth factor, $5 \mu \mathrm{g} / \mathrm{ml}$ insulin, $50 \mathrm{ng} / \mathrm{ml}$ dexamethasone, and $5 \mu \mathrm{g} / \mathrm{ml}$ transferrin) similar to that described by Maurer (1986) for MRC-5 cells. To facilitate attachment of the cells growing in $1 \%$ serum, the $T$-flask culture surface was normally coated with poly-D-lysine by modification of the method described by Maurer (1986). One-half $\mathrm{ml}$ of $0.1 \mathrm{mg} / \mathrm{ml}$ poly-D-lysine (Sigma Chemical Co.) was pipetted into each T-25 flask and allowed to coat all culture surfaces. After $10 \mathrm{~min}$, the poly-D-lysine was pipetted off and the $\mathrm{T}$ flask washed twice with Balanced Salt Buffer. In the $1 \%$ serum experiments, control cells in $10 \%$ serum were also grown in identical poly-D-lysine coated plates to control for any possible effects of poly-D-lysine.

\section{RESULTS}

\section{Long-term growth in low serum media supplemented with growth factors}

In many tests of the ability to support mammalian cells in serum-free culture, the medium found to give the most success was a 1:1 mixture of Dulbecco's Modified Eagle's Medium (DME) and Ham's Nutrient Mixture F-12 (Orly et al., 1980; Barnes and Sato, 1980; Loo et al., 1987). We have adopted the DME/F-12 medium for all of our tissue culture. Based on the available data from the literature (see review, Maurer, 1986) and a few preliminary experiments with our MRC-5 cells, we selected four growth factor supplements to add to the DME/F-12 media: $10 \mathrm{ng} / \mathrm{ml}$ epidermal growth factor, $5 \mu \mathrm{g} / \mathrm{ml}$ insulin, $50 \mathrm{ng} / \mathrm{ml}$ dexamethasone, and 5 $\mu \mathrm{g} / \mathrm{ml}$ transferrin.

In other preliminary experiments, we found that DME/F-12 media supplemented with growth factors in the absence of serum supported the growth of HeLa and human septum carcinoma RPMI cells. However, MRC-5 cells cultured in this serum-free medium divided only four or five times before all division ceased (data not shown). We tried various changes in growth factor concentrations but were unable to obtain sustained growth of MRC- 5 cells in defined media with zero serum concentration. Supplementation of the media with $0.5 \%$ serum did stimulate growth but the cells still rapidly deteriorated and stopped proliferating after a few generations (data not shown). In contrast, when MRC-5 cells were cultured in the DME/F-12 media plus growth factors plus $1 \%$ serum, the growth rate was nearly normal for many population doublings as long as the culture surfaces of the $T$ flasks were precoated with poly-D-lysine to enhance all cell attachment (Fig. 1A and B). In the absence of poly-D-lysine precoating, the cells initially grew 

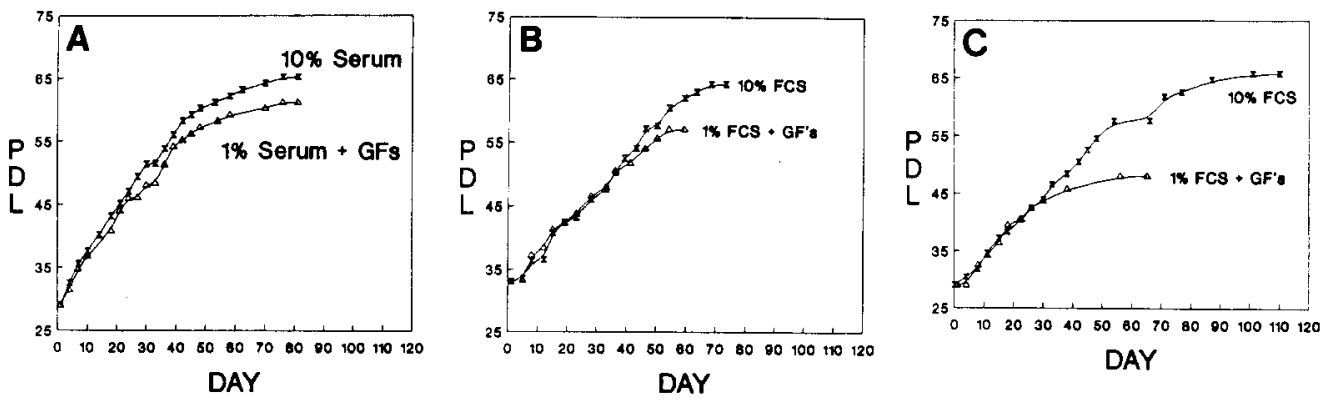

FIG. 1. Long-term growth in $1 \%$ and $10 \%$ serum. Human MRC-5 fibroblasts were cultured in DME/F-12 media containing $1 \%$ bovine fetal calf serum and growth factors $(\triangle-\triangle-\triangle-\triangle)$ or $10 \%$ bovine fetal calf serum without added growth factors $(\bar{X}-\bar{X}-\bar{X}-\bar{X})$. $A$ and $B$ are two separate experiments using $T$ flasks precoated with poly-D-lysine. $\mathrm{C}$ represents an experiment performed without precoating culture surfaces with poly-D-lysine. Each data point is the mean PDL calculated from two replicate plates.

normally but abruptly stopped proliferating at population doubling levels below 50 (Fig. 1C). Growth factors are required for culturing MRC-5 cells in media supplemented with only $1 \%$ serum since the cells stopped growing within a few divisions if growth factors were omitted (data not shown).

The maximum population doubling level reached for each experiment is given in Table 1 . MRC-5 cells cultured in $1 \%$ serum consistently have a lowered proliferative potential. One likely reason for this lowered growth potential in $1 \%$ serum is the characteristic poor attachment of older cells to the culture surface. Two lines of evidence support this hypothesis. First, in the absence of poly-D-lysine which promotes attachment, the maximum population doubling level reached is much lower (Fig. 1C and Table 1). Second, late passage MRC-5 cells (PDL of $>55$ ) when shifted from $10 \%$ to $1 \%$ serum have reduced attachment and growth in $1 \%$ serum within two generations (data not shown), indicating that cell age at the time of culturing in low serum

Table 1. Proliferative capactTy of MrC-5 cells cultured in various MEDIA

\begin{tabular}{lccccc}
\hline & \multicolumn{2}{c}{ Experiment 1} & & \multicolumn{2}{c}{ Experiment 2} \\
\cline { 2 - 3 } \cline { 5 - 6 } \% Serum \pm GF's & $P D L$ Limit & Days & & PDL Limit & Days \\
\hline $10 \%$ Serum - GF's & 65 & 76 & & 64 & 68 \\
$1 \%$ Serum + GF's & 61 & 76 & & 57 & 54 \\
$10 \%$ Serum - GF's & 64 & 68 & & - & - \\
(no poly-D-lysine) & & & & - \\
$1 \%$ Serum + GF's & 48 & 56 & & - & - \\
(no poly-D-lysine) & & & & & \\
$10 \%$ Serum - GF's & 65 & 101 & & 65 & 74 \\
$10 \%$ Serum + GF's & 72 & 103 & & 72 & 77 \\
\hline
\end{tabular}

For each medium, the maximum population doubling level reached (PDL limit) is shown along with the number of days it took to reach the postreplicative state. 

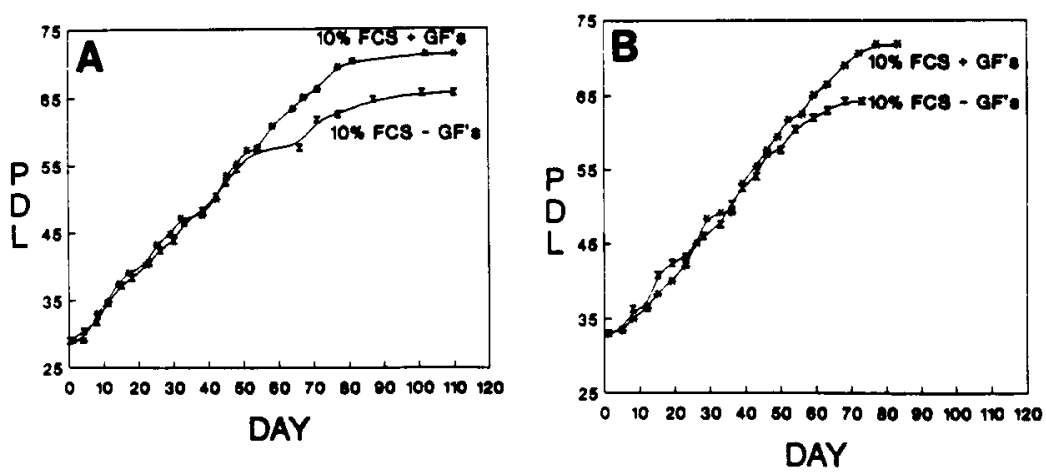

FIG. 2. Long-term growth in $10 \%$ serum with and without growth factors. Human MRC-5 fibroblasts were cultured in DME/F-12 media containing $10 \%$ bovine fetal calf serum and further supplemented with (*-*_*_*) or without $(\overline{\mathrm{X}}-\overline{\mathrm{X}}-\overline{\mathrm{X}}-\overline{\mathrm{X}})$ growth factors $(10 \mathrm{ng} / \mathrm{ml}$ epidermal growth factor, $5 \mu \mathrm{g} / \mathrm{ml}$ insulin, $50 \mathrm{ng} / \mathrm{ml}$ dexamethasone, and $5 \mu \mathrm{g} / \mathrm{ml}$ transferrin). A and $B$ represent two separate experiments.

is the critical variable rather than the absolute length of time spent in $1 \%$ serum media. The above evidence is also consistent with a general loss of cellular homeostasis with age which then leads to a lower growth capacity in the presumably stressful $1 \%$ serum media.

\section{Long-term growth in $10 \%$ media supplemented with growth factors}

As a control for the effect of adding growth factors to media with $1 \%$ serum, we have supplemented DME/F-12 media containing $10 \%$ serum with growth factors. We have observed that $10 \%$ serum plus growth factors have no effect on the early rate of division but does significantly increase the division potential of late passage cells (Fig. 2 and Table 1). This increase in proliferative capacity in $10 \%$ serum plus growth factors may simply reflect the inclusion of a glucocorticoid (dexamethasone) in our growth factor mix, since Cristofalo (1979) has demonstrated that glucocorticoids enhance the long-term growth of human fetal lung fibroblasts by increasing maximum proliferative capacity. Alternatively, the enhanced doubling potential may be caused by the increased levels of one or more of the other added growth factors. Our preliminary experiments suggest that the addition of epidermal growth factor alone does not lead to changes in proliferative capacity of late-passage cells (data not shown). However, we have not done experiments using single factors throughout the life span to test their effects and one study (Kaji and Matsuo, 1983) has reported a 5\% increase in life span after growing cells in media supplemented with serum plus $5 \mathrm{ng} / \mathrm{ml}$ epidermal growth factor.

\section{Morphological characteristics accompanying growth in $1 \%$ serum}

MRC-5 cells cultured in DME/F-12 media with $1 \%$ serum and added growth factors have an altered morphology (Fig. 3). In early passage, the cells in $1 \%$ serum.(Fig. 3A) appeared normal in comparison to control cells in $10 \%$ serum (Fig. 3C). However, cell orientation was altered so that the fibroblasts in $1 \%$ serum plus growth factors (Fig. 3A) formed less ordered arrays. In late passage, control MRC-5 cells in 10\% serum appeared larger and less elongated (Fig. 3D) 

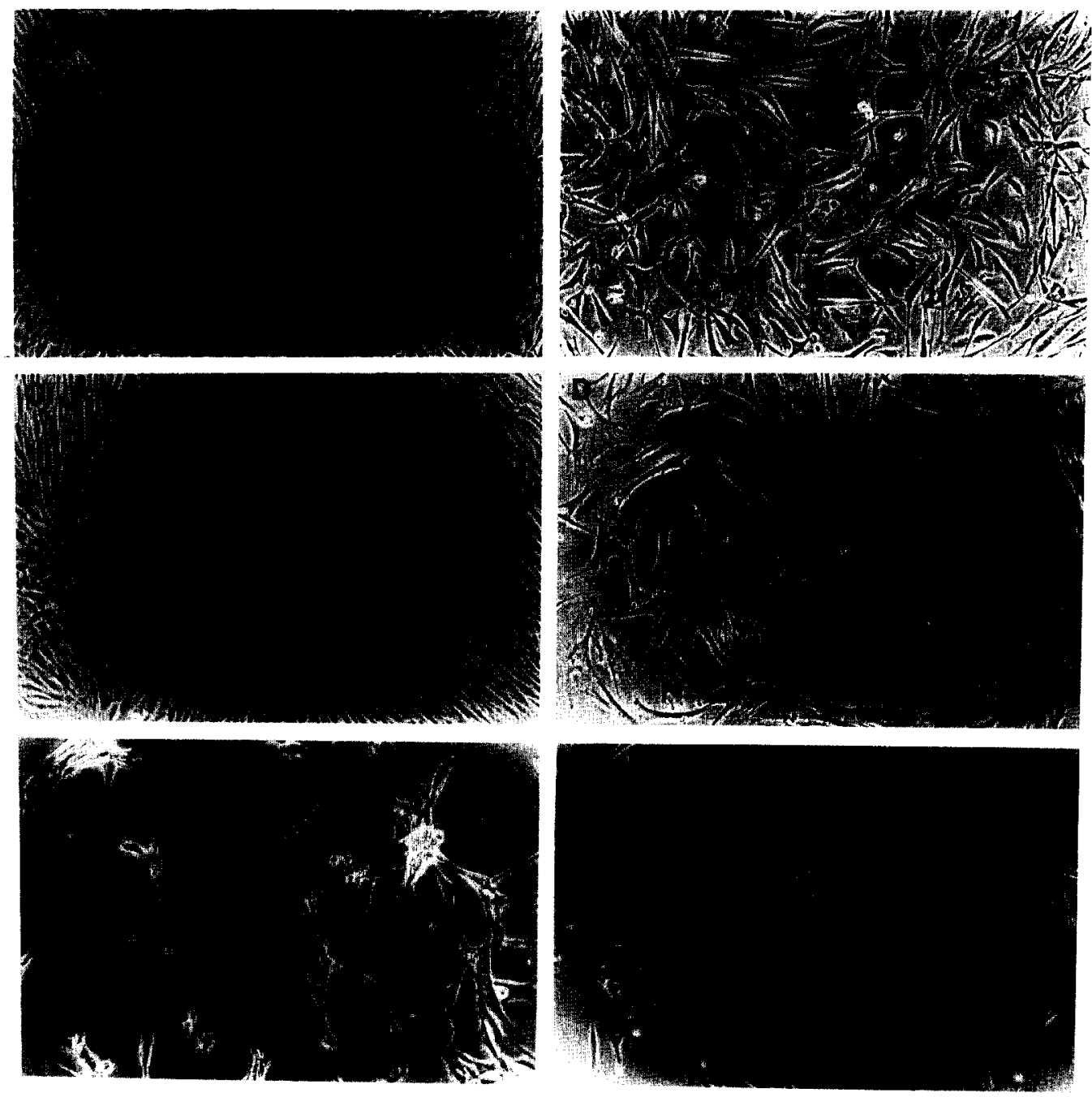

FIG. 3. Morphological characteristics of cells grown in 1\% or $10 \%$ serum. MRC-5 cells were cultured in DME/F-12 media containing either $10 \%$ fetal calf serum (C and D) or $1 \%$ serum plus growth factors (A, B, and F). The population doubling levels are: young, PDL of 28 (A and C) or old, PDL of 61 (B, D, and F). MRC-5 cells in frame E were cultured in $10 \%$ fetal calf serum plus growth factors and shifted to $1 \%$ fetal calf serum for the last four doublings (final PDL is 65).

while cells in $1 \%$ serum plus growth factors appeared to retain much of their original youthful-looking appearance even in the terminal stages of growth (Fig. 3B). However, with increased population doubling level, cells cultured in $1 \%$ serum plus growth factors had an increase in the number of cell clusters (Fig. 3F and data not shown) which are never seen in control cells cultured in $10 \%$ serum in the absence of added growth factors.

The morphological differences between control cells and cells cultured in $1 \%$ serum plus growth factors could be due to the low serum, to the added growth factors, or to a combination 
of the two. To test the importance of growth factors, MRC-5 cells were cultured in $10 \%$ serum and added growth factors. Our unpublished data show that growth factor-stimulated fibroblasts in $10 \%$ serum have most of the morphological characteristics found in cells cultured in $1 \%$ serum plus growth factors. As in $1 \%$ serum, our mix of growth factors generates late-passage cultures with smaller youthful-looking cells (results not shown). These $10 \%$ serum cultures also accumulate disordered cell clusters as is found in cultures in low serum plus growth factors. Our results indicate that the inclusion of added growth factors is the most significant variable in altering cell morphology.

The last question which we have addressed is whether the morphological differences observed on culturing cells in different media occurs slowly or rapidly on changing media conditions. Figure 3E shows that late-passage MRC-5 cells in 10\% serum (Fig. 3D) can rapidly adopt the youthful growth-factor-induced phenotype when transferred to media containing $1 \%$ serum plus growth factors. These data suggest that older cells have considerable morphological plasticity which can be triggered by changes in the concentration of growth factors.

\section{DISCUSSION}

It is widely accepted that normal diploid animal cells have a limited proliferative capacity in vitro. However, two independent studies have reported that putative normal rodent cells can have an unlimited life span if cultured in little or no serum (Ambesi-Impiombato et al., 1980; Loo et al., 1987). In view of the fact that rodent cells can spontaneously immortalize, it is difficult to definitively prove that these cells are normal. Thus, the role of serum in limiting the proliferative capacity of normal cells needs to be retested by culturing normal human cells, which do not undergo spontaneous immortalization, in low serum media. In the present study we have carried out long-term growth studies on diploid human MRC-5 cells in $1 \%$ serum and found no lengthening in cellular life span.

Our results confirm the study of Kan and Yamane (1982) who cultured human fetal lung fibroblasts in serum-free media and found no significant difference in life span. However, Kan and Yamane only observed long-term growth of human fibroblasts when $5 \mathrm{~g}$ per liter bovine serum albumin (BSA) was included in the serum-free medium. The use of such a large BSA concentration could lead to the introduction of an unknown quantity of serum-inhibitory factors. In another study using a low-protein serum-free media supplemented with lipids (Bettger $e$ t al., 1981), only short-term growth studies were undertaken and the rate of MRC-5 cell growth was reported to slow to one-fifth of the rate found using media supplemented with optimal serum concentrations. Given that no one has succeeded in designing a low-protein serum-free media which can support normal long-term growth of diploid human fibroblasts, we have favored lowering the serum content by $90 \%$ to the alternative of adding an undefined mix such as BSA to serum-free media. Using this strategy we can be fairly certain that any potential inhibitory factor will be 10 -fold lower than is the case when the cells are cultured in $10 \%$ serum.

Since we have retained $1 \%$ serum in our media, we can not completely rule out the possibility that the concentrations of the remaining inhibitory factors are still above what is functionally required for growth inhibition. However, we think that the existence of a large excess of inhibitory factors in serum is unlikely for several reasons. First, we note that cellular senescence is a long process with over 50 cumulative population doublings before growth inhibition is observed. If serum growth inhibitors are in such vast excess in serum, it is not clear why the inhibition of MRC-5 growth is only observed after 50 population doublings. Second, short-term growth in serum is known to be affected by the balance of growth-promoting and growth- 
inhibiting serum factors (Roberts et al., 1985; Tucker et al., 1984; Takehara et al., 1987). We know that growth factors are not in great excess in our normal media plus $10 \%$ serum because MRC-5 cells grew poorly in medial plus $1 \%$ serum in the absence of added growth factors (data not shown). If negative growth factors are responsible for the limit to long-term growth of MRC-5 cells, a 10-fold reduction in serum accompanied by growth factor addition would drastically alter the balance of growth-promoting and growth-inhibiting factors and should lead to a lengthening of cell life span. The fact that we do not see any lengthening in life span with a 10-fold reduction in growth-inhibiting factors suggests that growth-inhibitors are not the cause of MRC-5 senescence.

Another factor complicating the interpretation of our experiments is that the MRC- 5 cells had been cultured in media plus $10 \%$ serum for more than 25 population doublings before growth in media with low serum. This early exposure to high serum concentrations may be sufficient to commit the cells to a senescence pathway. This possibility seems unlikely since cells committed to a particular differentiated state characteristically exhibit phenotypic changes within a few divisions of the initiating event. In the case of mouse embryo cells selected for growth in serum-free media, addition of $10 \%$ serum induces growth inhibition and crisis in less than 10 divisions (Loo et al., 1987). In contrast, MRC-5 cells can divide for at least 30 doublings in low serum media before the onset of the nonproliferative state.

If serum is not a major contributor to senescence in human fibroblast cells, the question remains as to why some rodent cell lines behave like immortalized cells when cultured in little or no serum and undergo senescence and crisis when cultured in media plus $10 \%$ serum (Ambesi-Impiombato et al., 1980; Loo et al., 1987). One likely possibility is that the growth-inhibiting effect of serum on these apparently immortalized cell lines simply reflects a difference in cell type. For example, transforming growth factor- $\beta$ (TGF- $\beta$ ), the most studied growth-inhibiting serum factor, is a potent growth inhibitor for most epithelial cells while the growth of fibroblast cells is actually stimulated with exposure to TGF- $\beta$ (Roberts et al., 1985; Tucker et al., 1984; Takehara et al. 1987). Thus, we can not rule out the possibility that the long-term growth of human epithelial cells might be more sensitive to serum factors than are the lung fibroblasts studied here.

We have also reported that significant changes in morphology accompany growth of MRC-5 cells in $1 \%$ serum plus growth factors. MRC-5 cells cultured in $1 \%$ serum largely retain their youthful appearance even when the highest population doubling levels have been reached. Heterogeneity of size and shape which naturally occurs in MRC-5 cells cultured in $10 \%$ serum is muted in cells cultured in $1 \%$ serum plus growth factors. Moreover, this change in morphology can occur in a matter of days if an old population of cells cultured in $10 \%$ serum is suddenly shifted to $1 \%$ serum (compare Figs. 3D and 3E). The morphological changes in low-serum media are also reversed when old cells are shifted from $1 \%$ serum back to $10 \%$ serum (data not shown).

The changes in cell morphology with $1 \%$ serum are reminiscent but opposite in character to that seen when MRC-5 are cultured in retinoic acid. Young MRC-5 cells treated with retinoic acid for several doublings soon take on the heterogenous morphological characteristics of old populations (Wistrom, unpublished observations). However, this senescence-like morphological appearance is entirely reversible on the removal of retinoic acid (data not shown).

The growth experiments in $1 \%$ serum and retinoic acid demonstrate the existence of a surprising degree of plasticity in the cell morphology of both young and old cells. These results indicate that morphological characteristics are not always reliable indicators of senescence and suggest caution in using morphological criteria to determine the age of a fibroblast lineage. 
Acknowledgments - Cheryl Wistrom was supported by a NIH predoctoral fellowship in developmental biology. This research was supported by the American Federation for Aging Research.

\section{REFERENCES}

AMBESI-IMPIOMBATO, F.S., PARKS, L.A.M., and COON, H.G. Culture of hormone-dependent functional epithelial cells from rat thyroids. Proc. Natl. Acad. Sci. 77, 3455-3459, 1980.

BARNES, D. and SOTO, G. Serum-free cell culture: A unifying approach. Cell 20, 817-855, 1980.

BETTGER, W.J., BOYCE, S.T., WALTHALL, B.J., and HAM, R.G. Rapid clonal growth and serial passage of human diploid fibroblasts in a lipid-enriched synthetic medium supplemented with epidermal growth factor, insulin, and dexamethasone. Proc. Natl. Acad. Sci. 78, 5588-5592, 1981.

CARREL, A. and EBELING, A.H. Age and multiplication of fibroblasts. J. Exp. Med. 34, 599-623, 1921.

CRISTOFALO, V.J. Hydrocortisone: A specific modulator of in vitro cell proliferation and aging. Mech. Ageing Dev. 9, 485-496, 1979.

EBELING, A.H. The permanent life of connective tissue outside of the organism. J. Exp. Med. 17, 273-285, 1913.

HAY, R.J. and STREHLER, B.L. The limited growth span of cell strains isolated from the chick embryo. Exp. Gerontol. 2, 123-135, 1967.

HAYFLICK, L. The limited in vitro lifetime of human diploid cell strains. Exp. Cell Res. 37, 614-636, 1965.

HAYFLICK, L. The cellular basis for biological aging. In: Handbook of the Biology of Aging, Finch, C. and Hayflick, L. (Editors), pp. 159-185, Van Nostrand Reinhold Co., New York, 1977.

HAYFLICK, L. and MOORHEAD, P.S. The serial cultivation of human diploid cell strains. Exp. Cell Res. 25, 585-621, 1961 .

JACOBS, J.P., JONES, C.M., and BAILLE, J.P. Characteristics of a human diploid cell designated MRC-5. Nature 227, $168-170,1970$.

KAJI, K. and MATSUO, M. Responsiveness of human lung diploid fibroblast ageing in vitro to epidermal growth factor: saturation density and life span. Mech. Ageing Dev. 22, 129-133, 1983.

KAN, M. and YAMANE, I. In vitro proliferation and life span of human diploid fibroblasts in serum-free BSA-containing medium. J. Cell Phys. 111, 155-162, 1982.

LOO, D.T., FUQUAY, J.I., RAWSON, C.L., and BARNES, D.W. Extended culture of mouse embryo cells without senescence: Inhibition by serum. Science 236, 200-202, 1987.

MAURER, H.R. Towards chemically-defined, serum-free media for mammalian cell culture. In: Animal Cell Culture-A Practical Approach. Freshney, R.I. (Editor), pp. 13-31, IRS Press Limited, Oxford, 1986.

ORLY, J., SOTO, G., and ERICKSON, G. Serum suppresses the expression of hormonally induced functions in cultured granulose cells. Cell 20, 817-827, 1980.

PARKER, R.C. Human serum, age, and multiplication of homologous fibroblasts. Science 74, 181-1982, 1931.

ROBERTS, A.B., ANZANO, M.A., WAKEFIELD, L.M., ROCHE, N.S., STERN, D.F., and SPORN, M.B. Type $\beta$ transforming growth factor: a bifunctional regulator of cellular growth. Proc. Natl. Acad. Sci. 82, 119-123, 1985.

SCHNEIDER, E.L., BRAUNSCHWEIGER, K., and MITSUI, Y. The effects of serum batch on the in vitro life spans of cell cultures derived from old and young human donors. Exp. Cell Res. 115, 47-52, 1978.

TAKEHARA, K., LEROY, E.C., and GROTENDORST, G.R. TGF- $\beta$ inhibition of endothelial cell proliferation: Alteration of EGF binding and EGF-induced growth-regulatory (competence) gene expression. Cell 49, 415-422, 1987.

TUCKER, R.F., SHIPLEY, G.D., MOSES, H.L. and HOLLEY, R.W. Growth inhibitor from BSC-1 cells closely related to plated type $\beta$ transforming growth factor. Science 226, 705-707, 1984. 